\title{
Lyme carditis: a reversible cause of complete atrioventricular block
}

\author{
${ }^{1}$ IS Bhattacharya, ${ }^{2} \mathrm{M}$ Dweck, ${ }^{3} \mathrm{M}$ Francis \\ ${ }^{1}$ Foundation Year 1 Trainee; ${ }^{2}$ Specialist Registrar; ${ }^{3}$ Consultant, Cardiology Department, Victoria Hospital, Kirkcaldy, Fife, UK
}

ABSTRACT A 54-year-old American woman presented with an episode of syncope. This had occurred against a background of several days of dizziness and palpitations. Her medical history included Bell's palsy, which had been diagnosed three weeks earlier. On examination, she had a resting bradycardia of 31 beats per minute and her electrocardiogram demonstrated third-degree atrioventricular (AV) block. She was referred to cardiology for consideration of permanent pacemaker implantation. Given her facial nerve palsy and AV block, a diagnosis of Lyme borreliosis was suspected. Within 48 hours of initiation of ceftriaxone, she reverted to sinus rhythm, albeit with a marked first-degree AV block. Subsequent serology confirmed the diagnosis. Reversible causes of complete AV block should always be considered and appropriate therapy may avoid the need for permanent pacemaker insertion.

KEYWORDS Atrioventricular block, Lyme borreliosis, Lyme carditis
Correspondence to $M$ Francis, Cardiology Department, Victoria Hospital, Hayfield Road, Kirkcaldy KY2 5NG, UK

tel. +44 (0) 1592643355 e-mail mark.francis@faht.scot.nhs.uk

\section{CASE REPORT}

\begin{abstract}
A 54-year-old American woman on vacation was admitted to our hospital following an episode of syncope which had occurred against a background of several days of dizziness and palpitations. Three weeks previously she had developed left-sided facial weakness, which was diagnosed as Bell's palsy, and had been treated with a three-day course of prednisolone and acyclovir. The only feature of note in her medical history was manic depression, for which she was treated with lithium carbonate.
\end{abstract}

On examination, she was afebrile.There was no skin rash or lymphadenopathy. She had a resting bradycardia of 31 beats per minute and a blood pressure of $97 / 38 \mathrm{mmHg}$. There were no murmurs or signs of heart failure. Neurological examination revealed a left lower motor neurone seventh nerve palsy.

The patient's initial laboratory data were unremarkable. In particular, her electrolytes, cardiac enzymes and white cell count with differential were all normal and lithium levels were in the therapeutic range. Her chest X-ray was normal. Her electrocardiogram demonstrated thirddegree atrioventricular (AV) block (Figure IA). She was referred to cardiology for consideration of permanent pacemaker implantation.

However, given her facial palsy and heart block, a diagnosis of Lyme borreliosis was suspected. Blood was taken for Lyme serology. On closer questioning, the patient also reported being a keen walker in the hills of Massachusetts, but she could not recall any tick bites or skin rash in the previous 30 days.
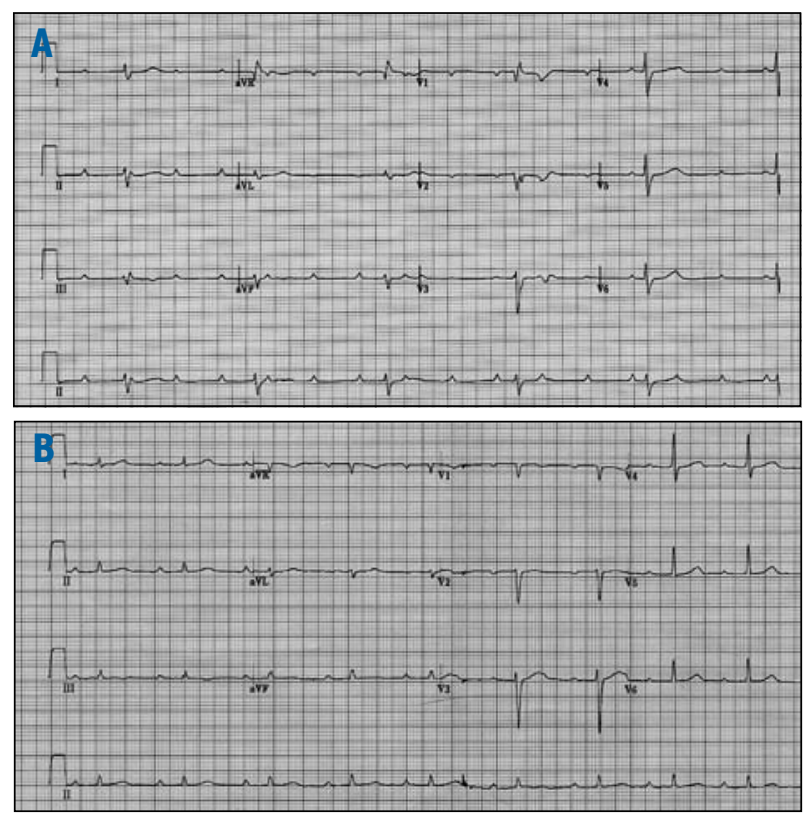

FIGURE I The patient's initial electrocardiogram showed a third-degree atrioventricular block (A). Within 48 hours of treatment with ceftriaxone, she reverted to sinus rhythm, albeit with marked first-degree atrioventricular block (B).

She was admitted to the coronary care unit, placed on continuous monitoring and treated with intravenous ceftriaxone, $2 \mathrm{~g}$ daily. Within 48 hours, she reverted to sinus rhythm, albeit with marked first-degree AV block (Figure IB). Thereafter, her hospital stay was uncomplicated and she remained in sinus rhythm with a shortening $P-R$ interval and her facial nerve palsy resolving. Subsequently, Lyme borreliosis was confirmed with positive serology and Western blot analysis. The 
patient has since returned to the USA and has suffered no long-term sequelae of her infection.

\section{DISCUSSION}

Lyme borreliosis is a multisystem disease caused by infection with the spirochaete Borrelia burgdorferi.' It is one of the most common tickborne infections in the northern hemisphere ${ }^{2}$ and is considered endemic in the highlands of Scotland. ${ }^{3}$ The clinical manifestations of Lyme borreliosis are classically divided into three stages: early localised, early disseminated and late disease. Early localised disease generally occurs several days or up to one month after the initial tick bite. An influenza-like illness may occur and is often accompanied by the erythema migrans rash. The early disseminated stage occurs weeks or months after the erythema migrans rash and is characterised by neurological symptoms and musculoskeletal complaints. Isolated facial nerve palsy is a common neurological manifestation. ${ }^{4}$ Finally, the late stage occurs several months to years after the erythema migrans rash and is characterised by a monoarthritis or oligoarthritis and the development and progression of neurological sequelae. ${ }^{1,46}$ The diagnosis is suspected clinically and confirmed by the detection of antibodies to the spirochaete. False positive tests may occur with enzyme-linked immunoabsorbent assay, and Western blot analysis should be used for confirmation. ${ }^{1.4}$

Cardiac manifestations occur in about $10 \%$ of patients with untreated Lyme borreliosis. ${ }^{4}$ Other systemic features may also be present, as occurred in this case. Varying degrees of $\mathrm{AV}$ block are the most common feature of Lyme carditis. In addition, pericarditis, endocarditis, myocarditis, pericardial effusion, myocardial infarction, coronary artery aneurysm, QT interval prolongation, tachyarrhythmias and congestive heart failure have been reported.' Myopericarditis is rare but may lead to transient cardiomegaly or pericardial effusion with non-specific ST and T wave changes on the electrocardiogram. ${ }^{7}$

\section{REFERENCES}

I Fish AE, Pride YB, Pinto DS. Lyme carditis. Infect Dis Clin North Am 2008; 22:275-88. doi:10.1016/j.idc.2007.12.008

2 Naik M, Kim D, O'Brien F et al. Lyme carditis. Circulation 2008; I 18: I88I-4. doi:I0.1 I6I/CIRCULATIONAHA. 108.766576

3 Mavin S, Hopkins PC, MacLennan A et al. Urban and rural risks of Lyme disease in the Scottish Highlands. Scott Med J 2009; 54:24-6.

4 Steere AC. Lyme disease. N Engl J Med 200I; 345:II5-25. doi:10.1056/NEJM200107/23450207
TABLE I Causes of atrioventricular block

\begin{tabular}{|l|l|l|}
\hline \multicolumn{2}{|l|}{ Congenital } \\
\hline Acquired & Irreversible & $\begin{array}{l}\text { Degenerative } \\
\text { Infiltrative } \\
\text { Collagen vascular disease } \\
\text { Neuromuscular disease }\end{array}$ \\
\cline { 2 - 3 } & $\begin{array}{l}\text { Potentially } \\
\text { reversible }\end{array}$ & $\begin{array}{l}\text { Myocardial infarction/ischaemia } \\
\text { Infection } \\
\text { Drugs } \\
\text { Electrolyte disturbance }\end{array}$ \\
\hline
\end{tabular}

The choice of antibiotic treatment for Lyme borreliosis depends on the stage of the disease. Early disease can be treated with oral doxycycline, $100 \mathrm{mg}$ twice a day for 14 days. Extracutaneous involvement in stage two requires more intensive treatment to eradicate infection and prevent late complications. Intravenous ceftriaxone, $2 \mathrm{~g}$ daily, is given in these cases. ${ }^{8}$ As in this case, it is often effective in leading to a rapid resolution of the heart block associated with carditis.

The causes of AV block can be divided into congenital and acquired, with some causes of the latter being reversible (Table I). In elderly patients, third-degree AV block is most often due to degenerative disease of the conducting system. ${ }^{7}$ In these patients, permanent pacemaker implantation is usually indicated. However, in younger patients, a reversible cause of AV block should always be considered before submitting them to pacemaker implantation. This case of Lyme borreliosis, promptly treated with the appropriate antibiotic, provides a clear illustration of this point.

\section{CONCLUSION}

Reversible causes of AV block should always be considered prior to pacemaker insertion. This case provides an unusual example of reversible AV block.
5 Hengge UR, Tannapfel A, Tyring SK et al. Lyme borreliosis. Lancet Infect Dis 2003; 3:489-500. doi:I0.10I6/SI473-3099(03)00722-9

6 Wormser GP. Early Lyme disease. N Engl J Med 2006; 354:2794-80I. doi:I0.1056/NEJMcp06II8I

7 Hajjar RJ, Kradin RL. Weekly clinicopathological exercises. Case 17. N Engl J Med 2002; 346: 1732-8.

8 Wormser GP, Nadelman RB, Dattwyler RJ et al. Practice guidelines for the treatment of Lyme disease. Clin Infect Dis 2000; 3I(Suppl I): I-I4. doi:I0. I086/3|4053 